\title{
Nomadic identities, archipelagic movements and island diasporas
}

\author{
May Joseph
}

Pratt Institute, USA

mjoseph@pratt.edu

\begin{abstract}
Nomadic identities have shaped island histories and archipelagic communities since the emergence of the Westphalian state. In the era of postcoloniality, settler colonial realities, decolonial movements, and now climate change, the processes of forced and involuntary migrations as well as states of internal disaffiliation have accentuated the discontinuities between citizenship and island subjects. This special section of Island Studies Journal offers a comprehensive look at how island mobilities and archipelagic diasporas in formation have shaped contemporary notions of nomadic belonging. Islands have historically been entities whose political struggles for citizenship have been frequently repressed. This section explores island becoming, displaced and migrant archipelagic affiliations, and emerging historical understandings of nomadic citizenship.
\end{abstract}

Keywords: islands, archipelagic, citizenship, migration, indigenous, diaspora, climate

https://doi.org/10.24043/isj.161 • Received May 2021, accepted May 2021

(C) Island Studies Journal, 2021

\section{Nomadic identities}

What does the notion of nomadic identities signify today, and why does this matter to a theory of islands and thinking through the archipelago? In 1999, I published a book titled Nomadic identities: The performance of citizenship (Joseph, 1999). It addressed the forced displacement of Asians from East Africa, through their multiply migrated histories. Nomadic identities interrogated the questions: Who is a citizen, and what does it means to occupy the legally amorphous space of the nomadic?

The book was shaped by the political and racial tensions of economic nationalization which led to the articulation of Asians in East Africa as inauthentic citizens. This resulted in mass deportations of Asians from Uganda, Kenya and Tanzania through the mid-1970s. The 1970s was an era of mass demobilizations, in East Africa, in Cambodia, in Vietnam, in East Bengal which would eventually become Bangladesh, in Biafra. There were forced displacements of peoples that were reshaping how belonging would be played out across the 
global south. People fled by boat, by plane and by foot. This era of nomadic identity formation was one born of sovereignty, territorial disputes and immigration histories. It was a conceptualization that was territorially bound, though consistently shaped by oceanic migrations. This earlier moment also framed the materialization of conditions that have come to stay, particularly the idea of non-citizens, migrants, internally displaced peoples, and refugees, all shaped to varying degrees by the articulations of the concept of nomadic identities, forms of identification that were in flux.

\section{Archipelagic movements}

Island studies and the analytics of island mobilities have expanded the complexities of what it means to be culturally and legally nomadic fifty years after the expulsion of Asians from East Africa. Ilan Kelman (2018) points out that small island populations have historically tended to migrate over time. Migrancy is part of the structuring necessities of island populations over the long duree. Kelman cautions against the easy assumption that living on low-lying islands in the era of rising oceans necessarily implies island migration or displacement that lacks in agency. He argues that many small island states are actively strategizing and making efforts to cope with climate as agentic participants. Keeping these correctives in mind, the ongoing challenges to archipelagic communities around the global south in particular suggest uneven, informal and coercive instances of island mobilities resulting in nomadic identities in formation. Not all these dispersals are necessarily migrant. Some verge on what Giorgio Agamben (1998) calls bare life, as in the case of the Rohingyas of Myanmar.

The historic study of islands demonstrates that people do not necessarily have to move or leave their island homes to experience cultural or legal states of nomadic citizenship (Gómez-Barris \& Joseph, 2019; Nadarajah \& Grydehøj, 2016). The cases of Hawaii, Marshall Islands, Puerto Rico and the Mariana Islands demonstrate how indigenous populations did not have to leave their island homes to experience a sense of being legally disenfranchized, alienated from indigenous rights to their own island states amidst the occupier's culture (Kauanui, 2008; Aikau \& Gonzalez, 2019; Schwartz, 2019; Garriga-López, 2019; Perez, 2019; Faris, 2019). These particular island communities accentuate the conundrum that certain island cultures are legally displaced from their own land without having ever left it. They are coerced into a condition of nomadic belonging, through settler colonial occupation. For them, the condition of nomadic identity is a place of disavowal, of deferred citizenship and belonging. It is a state to be contested and decolonized. 
Other island communities such as those of the Caribbean (Perdekaris, 2021; GarrigaLópez, 2019; Finneran \& Welch, 2020) present us with entirely different sets of pressures affecting migrant and displaced island identities in formation due to climate change in Belize, Puerto Rico, Barbuda and Balliceaux. The very locationality of islands vis-à-vis the mainland and with regards to national cultures predicated on centralized land-bound discourses, opens up the fractures of island belonging in many contexts across the world (Joseph, 2019). Particular relationalities of archipelagoes to notions of belonging, citizenship processes and land claims, such as Jaffna in Sri Lanka, and the Arakaan archipelago, foreground the shifting realities of nomadic identities across the geopolitical spectrum.

Islands today are increasingly flashpoints of contested political identities. In the case of Bolghatty Island, Vypin Island, Fort Cochin Island and the archipelago of islands across the Kerala coast of South India, their histories of miscegenation and multi-religious syncretisms puts this region at direct odds with the Indian government's ideological stance of promoting the fiction of an originary pure Hindu India. The archipelagic coastline of Southern India is populated by poor Muslims and Christians alongside other histories of arrival, such as African, Jewish, Zoarashtrian, Bahai, which singularly disrupts the ethnonationalist claims of the central government. The islands and coastal communities of South India are an active instance of the ways in which island and coastal communities in the post-national moment are encountering a new challenge to their historic notions of self and belonging (Joseph, 2019).

Along the Sunderbans of the Bay of Bengal, the struggles between Rohingyan refugees to find safety amidst the already overcrowded mudflats of Bangladesh, their reluctant host country, is a tragic instance of nomadic island identities in the process of disappearance. The Rohingya populations of the Arakaan region of Myanmar are forced into states of inauthentic citizenship through coercive new laws and regulations that erase the histories of coastal and island Rohingya communities within Myanmar. These communities are at once redacted by their own state, Myanmar, and persons-non-grata in Bangladesh and India. All of this while they occupy the sinking mudflats of the outer islands of the Bengal delta shared by India and Bangladesh, a shifting sandbank archipelago of silt and mud.

\section{Island diasporas}

Islands, according to Peregrine Horden and Nicholas Purcell (2000), are sites of interdependence. They embody all-round connectivity. Islands are also places of narrow possibilities, where connectivities are not necessarily available even if they are technically 
present. The insularity of island ontologies perpetuates forms of narrowed options that make it difficult for indigenous or local communities to harness or fully exploit the potentiality of the connectivities that Horden and Purcell gesture to. For many islanders across the globe, leaving and starting afresh, braving the waters of the Indian Ocean for Zanzibaris (Bishara, 2017) or the Atlantic, leaving Cuba (Behar, 2013) or Haiti (Ulysse, 2017) is easier than drawing on the opportunities that are more difficult to access back home. Many of the service sector people I interviewed in Malé, Maldives were from the Andaman and Nicobar Islands and had arrived in Maldives via Sri Lanka. Others were from Sunderban region of Bangladesh, working in the Maldives, with the provisional idea that neither places were options for the long term. These states of nomadic identities of island communities throw open the precarious forms of belonging that island diasporas maintain with their homelands.

The ensuing essays probe the varied ways in which island communities are producing, and being produced as, nomadic identities. Relationality and an archipelagic approach to thinking through island diasporas inform their theories (Mahajan, 2021; Nadarajah, 2021; Baldacchino, 2006; DeLoughrey, 2007; Grydehøj et al, 2020; Pugh, 2013). Islands are urban artifacts and the archipelago is an urban model, Brian McGrath (2021) proposes. Together, they present an ocean polity of constructed self-sufficient patches, islands, and archipelagos. In this space, fear and hope thread states of disrupted island becoming (Kelman \& Stojanov, 2021). The intersection of race and migration in the formation of nomadic identities at sea among indigenous and Black diasporas resituates ocean mobilities in the face of imperial and decolonial logics (Guerin, 2021; Mahajan, 2021; Lam, 2021; Perdikaris et al, 2021). These transoceanic crossings highlight different histories of multiple migrations in states of affective reinvention (Nadarajah, 2021).

\section{References}

Agamben, G. (1998) Homo sacer: Sovereign power and bare life. Stanford University Press. https://doi.org/10.1515/9780804764025

Aikau, H. K., \& Gonzalez, V. V. (2019). Curating a decolonial guide: The Detours project. Shima, 13(2), 11-21. https://doi.org/10.21463/shima.13.2.04

Behar, R. (2013) Traveling heavy: A memoir in between journeys. Duke University Press.

Baldacchino, G. (2006). Island, island studies, island studies journal. Island Studies Journal, 1(1), 3-18.

Bishara, F. A. (2017). A sea of debt: Law and economic life in the Western Indian Ocean, 17801950. Cambridge University Press. https://doi.org/10.1017/9781316659083.003

DeLoughrey, E. (2007). Routes and roots: Navigating Caribbean and Pacific Island literature. University of Hawaii Press. https://doi.org/10.1515/9780824864187 
Faris, H. J. (2019). Sisters of ocean and ice: On the hydro-feminism of Jetñil-Kijiner and Aka Niviâna's's 'Rise: From one island to another'. Shima, 13(2), 76-99. https://doi.org/10.21463/shima.13.2.08

Finneran, N., \& Welch, C. (2020). Mourning Balliceaux: Towards a biography of a Caribbean island of death, grief and memory. Island Studies Journal, 15(2), 255-272. https://doi.org/10.24043/isj.121

Garriga-López, A. (2019). Puerto Rico: The future in question. Shima, 13(2), 174-192. https://doi.org/10.21463/shima.13.2.13

Gómez-Barris, M., \& Joseph, M. (2019). Coloniality and islands. Shima, 13(2), 1-10. https://doi.org/10.21463/shima.13.2.03

Guerin, A. (2021). Shared routes of mammalian kinship: Race and migration in Long Island whaling diasporas. Island Studies Journal, 16(1), 43-61. https://doi.org/10.24043/isj.160

Grydehøj, A., Nadarajah, Y., \& Markussen, U. (2020). Islands of indigeneity: Cultural distinction, indigenous territory and island spatiality. Area, 52(1), 14-22. https://doi.org/10.1111/area.12520

Horden, P., \& Purcell, N. (2000). The corrupting sea: A study of Mediterranean history. Blackwell. Joseph, M. (2019). Sealog: Indian Ocean to New York. Routledge.

Joseph, M. (1999). Nomadic identities: The performance of citizenship. University of Minnesota Press. Kauanui, J. K. (2008). Hawaiian blood: Colonialism and the politics of sovereignty and indigeneity. Duke University Press. https://doi.org/10.1215/9780822391494

Kelman, I. (2018) Islandness within climate change narratives of Small Island Developing States (SIDS). Island Studies Journal, 13(1), 149-166. https://doi.org/10.24043/isj.52

Kelman, I., \& Stojanov, R. (2021). Islander migrations and the oceans: From hopes to fears? Island Studies Journal, 16(1), 23-42. https://doi.org/10.24043/isj.120

Lam, K. (2021). Island-raised but foreign-made: Lived experiences, transnational relationships, and expressions of womanhood among Cape Verdean migrant women in Greater Lisbon. Island Studies Journal, 16(1), 101-114. https://doi.org/10.24043/isj.71

Mahajan, N. (2021). Notes on an archipelagic ethnography: Ships, seas, and islands of relation in the Indian Ocean. Island Studies Journal, 16(1), 9-22. https://doi.org/10.24043/isj.147

McGrath, B. (2021). Island as urban artifact/archipelago as urban model. Island Studies Journal, 16(1), 81-100. https://doi.org/10.24043/isj.140

Nadarajah, Y. (2021). Future past I am a coolie-al...and I reside as an invisible island inside the ocean: Tidalectics, transoceanic crossings, coolitude and a Tamil identity. Island Studies Journal, 16(1), 155-172. https://doi.org/10.24043/isj.159

Nadarajah, Y., \& Grydehøj, A. (2016). Island studies as a decolonial project. Island Studies Journal, 11(2), 437-446.

Perdikaris, P., Boger, R., Gonzalez, E., Ibrahimpasic, E., \& Adams, J. D. (2021). Disrupted identities and forced nomads: A post-disaster legacy of neocolonialism in the island of Barbuda, Lesser Antilles. Island Studies Journal, 16(1), 115-134. https://doi.org/10.24043/isj.130

Perez, C. S. (2019). Guahan, the Pacific and decolonial poetry. Shima, 13(2), 22-29. https://doi.org/10.21463/shima.13.2.05 
May Joseph

Pugh, J. (2013). Island movements: Thinking with the archipelago. Island Studies Journal, 8(1), 9-24.

Schwartz, J. A. (2019). Waves of displacement and waves of development: Marshallese songfest competitions and cultural diplomacy in Springdale, Arkansas. Shima, 13(2), 116-134. https://doi.org/10.21463/shima.13.2.10

Ulysse, G. A. (2017). Because when God is too busy: Haiti, me and the world. Wesleyan University Press. 